\title{
IMPLEMENTASI BOX MODELING DAN CONTORING MODEL PADA ANIMASI MERAKIT PC MENGGUNAKAN 3DSMAX
}

\author{
Benyamin Jago Belalawe ${ }^{1}$, Mateus Mas Belalawe ${ }^{2}$ \\ Program Studi Teknik Informatika ${ }^{1}$, Program Studi Teknik Informatika ${ }^{2}$ \\ STIKOM Uyelindo Kupang ${ }^{1}$, STIKOM Artha Buana Kupang ${ }^{2}$ \\ ${ }^{1}$ qq_gerald@yahoo.com, ${ }^{2}$ belalawe@yahoo.com,
}

\begin{abstract}
Current technological developments, especially in the $3 D$ field experienced a lot of progress. $3 D$ Modeling is the process of creating $3 D$ objects that want to be expressed in a real visual form, both in the shape, texture and size of the object. Making $3 D$ models of objects or objects using a computer to make objects look more alive and in accordance with the original object. The method applied in PC assembly animation is the Modeling Box and Contoring Model using 3DSMax. The results of this study can provide a picture for beginners in assembling a PC.
\end{abstract}

Keywords : Box Modeling, Contoring Model, Animation, Assembling PC, 3DSMax.

\section{PENDAHULUAN}

Perkembangan teknologi dibidang animasi telah mengalami banyak kemajuan sehingga menjadi lebih kompleks dan canggih. Alasannya karena selain memiliki sudut pandang lebih luas dari obyek dua dimensi (2D) yang hanya mempunyai satu sudut pandang saja obyek tiga dimensi (3D) juga dinilai lebih interaktif dan imajinatif karena obyek akan sesuai dengan aslinya.

Pembelajaran dengan menggunakan media animasi dapat memberikan suatu kegiatan yang menyenangkan diamana dapat menciptakan proses pembelajaran yang efektif, menarik. Salah satu komponen penting dalam pembelajaran adalah media pembelajaran. Penyampaian informasi dengan memanfaatkan teknik visualisasi tiga dimensi ini sangat menarik, karena dapat menampilkan model tiga dimensi dari sebuah objek sebelum dibangun secara nyata. Visualisasi tiga dimensi merupakan penampilan informasi yang bersifat komplek kedalam bentuk visual [2]

Penggunaan multimedia dalam hal ini animasi mampu membuat suatu terobosan baru dalam menciptakan dinamika kemasan data dan informasi dengan cara yang berbeda bukan dengan teks statis tetapi dengan animasi teks, gambar, suara, video serta 3 dimensi. Dengan animasi merakit PC yang dibuat dapat sebagai media pembelajaran yang lebih menarik dan interaktif. Berdasarkan uraian tersebut maka dibuatlah animasi pembelajaran dengan tujuan dapat memberikan gambaran dan langkahlangkah dalam perakitan komputer.

\subsection{Rumusan Masalah}

Berdasarkan permasalahan tersebut maka dapat disimpulkan rumusan permasalahan sebagai berikut:

a. Bagaimana membuat sebuah animasi tiga dimensi merakit PC sebagai media Pembelajaran.

b. Bagaimana menggunakan Box Modeling dan Contoring Model dalam 3DSMax.

\subsection{Batasan Masalah}

Agar pembahasan tidak keluar dari topik, maka penulis membatasi permasalahan penelitian yaitu:

a. Pembuatan Animasi sebagai media pembelajaran yang didesain dengan studi kasus merakit PC

b. Animasi 3D menggunakan objek-objek 3DMAx 2013 Menggunakan Box Modeling dan Contoring Model dalam 3DSMax.

\subsection{Tujuan dan Manfaat Penelitian}

Tujuan dari penelitian ini adalah membuat Animasi sebagai media pembelajaran bagi pemula dalam merakit PC

\section{TINJAUAN PUSTAKA}

Aplikasi Simulasi 3 Dimensi Bangun Ruang Untuk Sekolah Dasar (SD) Berbasis 
Android. sebagai simulasi pembelajaran bangun ruang $3 \mathrm{D}$ yang bisa diimplementasikan dalam pembelajaran matematika sehingga muncul ketertarikan siswa dan membantu siswa dalam belajar sehari-hari. aplikasi ini juga dilengkapi dengan soal dan cara mengerjakannya. Hasil dari penlitian ini adalah aplikasi simulasi $3 \mathrm{D}$ bangun ruang berbasis android sebagai sarana pembelajaran bagi siswa SD yang berisi tentang macammacam bangun ruang, materi, rumus, serta contoh soaldan cara menyelesaikan soal yang dapat membantu para siswa agar mudah dalam mempelajari bangun ruang.[3]

Pengaruh Media 3ds Max Maker Terhadap Hasilbelajar Siswa. Menganalisis pengaruh media 3Ds Max Maker terhadap hasil belajar siswa pada Mata Pelajaran TIK Kelas XI Di MA Riyadlul Anwar Kabupaten Lombok Tengah Tahun Pelajaran 2018/2019. Teknik yang digunakan dalam menentukan populasi adalah tehnik studi populasi karena jumlah populasi 21 siswa. Metode pengumpulan data menggunakan metode tes sebagai metode pokok dan dokumentasi sebagai metode pelengkap. Untuk menganalisa data menggunakan rumus $t$-test. [5]

Pengembangan media pembelajaran teknik animasi 2 dimensi berbasis Adobe Flash untuk siswa kelas XI multimedia di SMK Muhamadiah Prambanan. Tujuannya adalah menghasilkan media pembelajaran Teknik Animasi 2 Dimensi dan mengetahui kelayakan media pembelajaran Teknik untuk mengetahui hasil belajar siswa setelah menggunakan media pembelajaran Teknik Animasi 2 Dimensi.[1]

Media pembelajaran menggunakan mac romedia flash, subyek dalam penelitian ini adalah ahli materi dan ahli media baik dari dosen dan guru mata pelajaran perakitan PC. Untuk mengetahui kelayakan produk media pembelajaran

maka dilakukan pengujian validitas dengan mengadopsi pendapat dari beberapa ahli (expert judgment). Penelitian ini menggunakan metode Riset dan pengembangan (Research and Development). Hasil dalam penelitian ini menunjukan bahwa secara garis besar media pembelajaran berbasis 3dsmax mata pelajaran perakitan PC layak digunak an sebagai media pembelajaran. Validasi ahli media memberikan penilaian bahwa media pembelajaran yang dihasilkan layak.[4]
Multimedia animasi pada materi diffusion coating dan respon mahasiswa selaku pengguna multimedia. Penelitian ini menggunakan metode design based research. Subjek penelitian adalah mahasiswa teknik mesin prodi D3 angkatan tahun 2015sebanyak 18 orang. Instrumen penelitian yang digunakan yaitu angket dan validasi ahli untuk multimedia animasi. Hasil penelitian diperoleh bahwa multimedia animasi difffusion coatingtelah layak untuk digunakan berdsarkan penilaian pakarahli materi dan media. Multimedia animasi yang telah dikembangkan dapat layak untuk digunakan dalam proses belajar mengajar diffusion coating. Respon dan ketertarikan pengguna multimedia animasi tinggi sehingga mudah untuk digunakan.6]

\section{METODE PENELITIAN}

\subsection{Studi Kepustakaan}

Dilakukan dengan mencari literatur pendukung penelitian yang mampu memberikan informasi yang memadai dalam menyelesaikan penelitian ini sertan membantu mempertegas teori-teori yang ada. Proses pengumpulan data dilakukan dengan menggunakan sumber-sumber yang terkait baik dari buku, jurnal, skripsi maupun internet

\subsection{Metode Observasi}

Observasi merupakan salah satu teknik pengumpulan data yang cukup efektif terhadap objek penelitian. Observasi dilakukan dengan cara mengadakan pengamatan langsung terhadap proses merakit PC

Melakukan tanya jawab langsung dengan prl mahasiswa untuk mengumpulkan data yang diperlukan secara face to face antara peneliti dan mahasiswa selaku objek dalam penelitian untuk memperoleh data yang dapat menjelaskan ataupun menjawab suatu permasalahan penelitian.

\subsection{Prosedur Pengembangan Animasi \\ Pembelajaran}

Prosedur pengembangan program menjelaskan secara rinci proses pembuatan media animasi 3D. Proses produksi terdiri dari tiga tahapan, yaitu pra produksi, produksi, dan pasca produksi seperti tertera pada bagan berikut

1. Tahap pra produksi, meliputi kegiatan persiapan alat produksi, yaitu seperangkat komputer dan software-software pendukung dalam hal ini software yang paling utama adalah 3DsMax 2013 dan software Pinnacle 2012 yang berfungsi 
sebagai software pengolah video Pembuatan Animasi.

2. Tahap produksi, meliputi pembuatan model perangkat keras komputer untuk membuat animasi sesuai langkahlangkam merakit PC sesuai dengan rancangan sebagai media pembelajaran kedalam bentuk grafis, animasi, teks, suara. Dari pembuatan desain grafis/animasi, maka akan diperoleh wujud nyata dari kerangka perancangan yang telah buat.

3. Tahap pasca produksi, meliputi kegiatan mengedit dan merender video, apakah ada kekurangan dalam video animasi merakit PC yang telah dibuat.

\subsection{Metode Pengembangan Animasi}

Terdapat beberapa tahap yang dilakukan yaitu studi literatur dengan mempelajari referensi-referensi yang terkait dengan penelitian, pengumpulan data dari beberapa nara sumber. Prosedur penelitian dapat dilihat pada gambar flowchart dibawah ini.

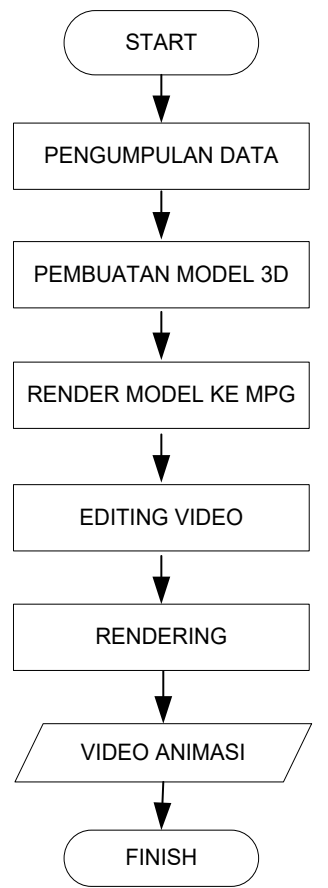

Gambar 1. Flowchart Prosedur Penelitian

\subsection{Pembuatan Model Perangkat Keras}

Dalam pembuatan animasi merakit PC 3D dibutuhkan beberapa perancangan awal. Pada penelitian ini menggunakan Box Model dan Contouring Model sebagai fitur-fitur yang di gunakan untuk memudahkan para pengguna untuk merakit PC.
Desain 3D Perangkat Keras utama komputer terdiri dari:

1. Desain Model 3D Chasing

Desain chasing menggunakan Box Model dengan disesuaikan dengan ukuran Chasing yakni Tinggi 40, Lebar $20 \mathrm{~cm}$ dan Panjang 40 $\mathrm{cm}$. Pada bagian ini di buat beberapa Slot tempat pemasangan untuk perangkat keras komputer diantaranya: Slot HDD, Slot CD/DVD, Port Komunikasi, Tombol Power dan Port Audio

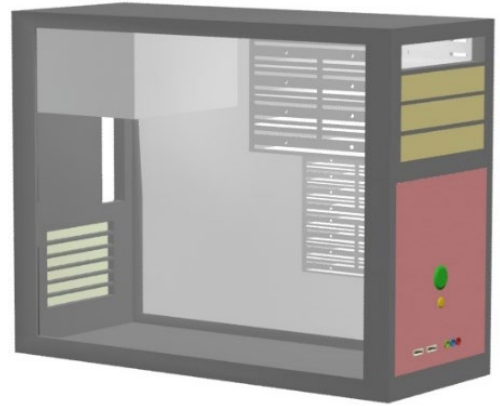

Gambar 2. Desain Model 3D Chasing 2. Desain Model 3D Motherboard Desain Motherboard menggunakan Box model dengan membuat beberapa slot dan beberapa perangkat bawaan daripada motherboart diantaranya slot PCI, slot AGP, slot Memori, Port komunikasi, 2 buah chipset, port Power dan port Kabel data.

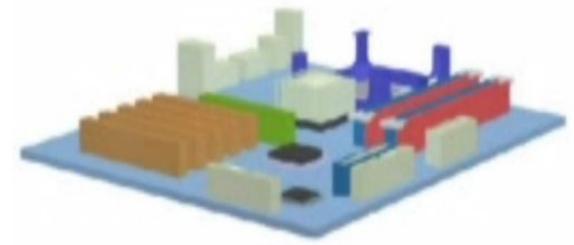

Gambar 3. Desain Model 3D Motherboard

\section{Desain Model 3D CD/DVD}

Desain model CD/DVD menggunakan model Box Model dimana pada perangkat ini terdapat tombol pembuka pintu dan port power dan port kabel data.

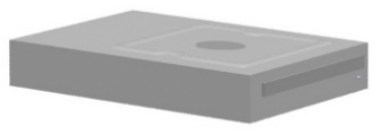

\section{Gambar 4. Desain Model 3D CD/DVD}

\section{Desain Model 3D HDD}

Desain model Harddisk menggunakan model Box Model dimana pada perangkat ini terdapat port power dan port kabel data. 


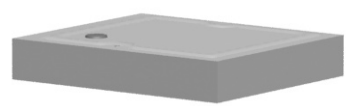

Gambar 5. Desain Model 3D HDD

5. Desain Model 3D Memory

Desain model Memory menggunakan model Box Model dimana pada perangkat ini terdapat beberapa Chip memory.

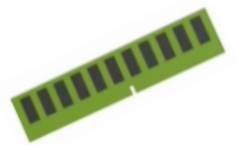

Gambar 6. Desain Model 3D Memory

6. Desain Model 3D Procecor

Desain model Memory menggunakan model Box Model dimana pada perangkat ini terdapat beberapa pin sebagai kaki prosesor.

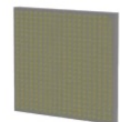

Gambar 7. Desain Model 3D Procecor

7. Desain Model 3D Heatsing

Desain Heatsing menggunakan model Box Model dimana pada perangkat ini dibuat beberapa lempengan-lempengan sebagi media pendingin dan pengait pengunci Heatsing

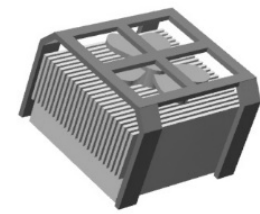

Gambar 8. Desain Model 3D Heatsing

8. Desain Model 3D Keyboard

Desain Keyboard menggunakan Box Model dimana pada perangkat ini dibuat beberapa tombol-tombol dari angka dan abjat pada keyboard serta beberapa tombol fungsi lainnya.

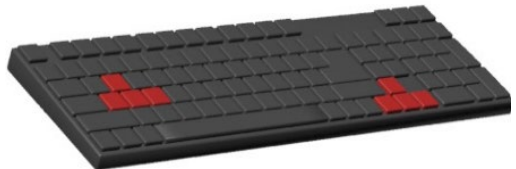

Gambar 9. Desain Model 3D Keyboard

9. Desain Model 3D Mouse

Desain Heatsing menggunakan model Box Model dimana pada perangkat ini dan Contoring Model sebagai pembentuk model Mouse

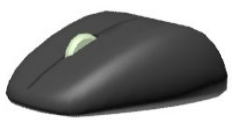

Gambar 10. Desain Model 3D Mouse

10. Desain Model 3D Monitor

Desain Heatsing menggunakan model Box Model dan Contoring Model untuk membentuk layar Monitor dan menambahkan kaki daripada monitor serta beberapa tombol fungsi pada layar monitor

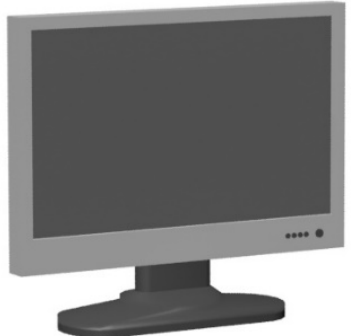

Gambar 11. Desain Model 3D Monitor

\section{HASIL DAN PEMBAHASAN}

Bagaian akhir animasi merakit PC ini adalah dengan mengan menggabungkan semua desain model perangkat keras computer menggunakan aplikasi Editing Film dengan menambahkan suara, teks dan effeck.

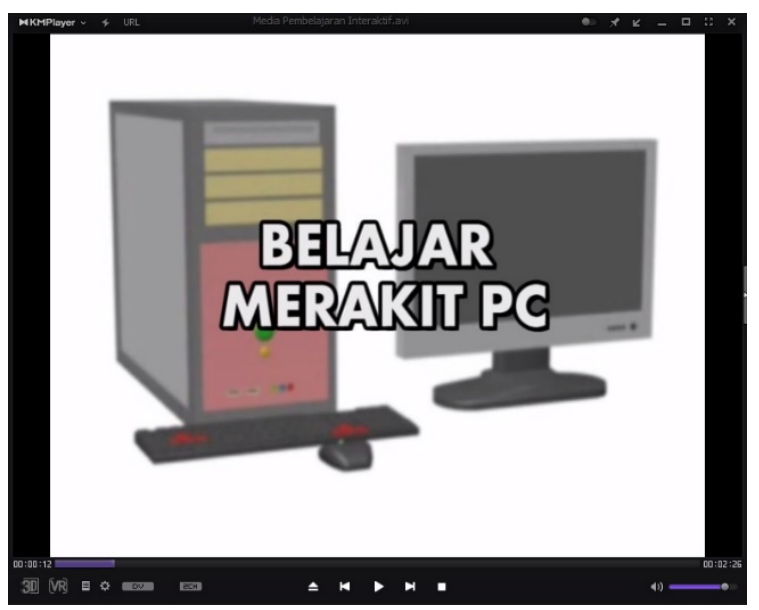

Gambar 11. Hasil Animasi Merakit PC

\section{KESIMPULAN}

\subsection{Kesimpulan}

Dari hasil penelitian yang dilakukan dapat disimpulkan bahwa:

a. Animasi 3D merakit PC dapat dipahami dan layak untuk digunakan sebagai media pembelajaran bagi Mahasiswa maupun masyarakat umum dalam mempelajari cara merakit komputer 
b. Pada animasi ini terdapat pula Teks sebagai penjelasan daripada langkahlangkah dalam merakit komputer.

\subsection{Saran}

Saran yang dapat berikan bagi penelitian yang berhunungan dengan animasi merakit PC ini adalah dapat menambahkan beberapa Model 3D lainya.

\section{DAFTAR PUSTAKA}

[1] Candra Agustina Pengembangan Media Pembelajaran Teknik Animasi 2 Dimensi Berbasis Adobe Flash Untuk Siswa Kelas XI Multimedia di SMK Muhammadiyah Prambanan, Skripsi, Program Studi Pendidikan Teknik Informatika Fakultas Teknik Universitas Negeri Yogyakarta, 2015.

[2] Chapman, N, Digital Multimedia, Andi Offset, Yogyakarta, 2004.

[3] Hotmian Sitohang dan Muliawardi Strianingsih, Aplikasi Simulasi 3 Dimensi Bangun Ruang Untuk Sekolah Dasar (SD) Berbasis Android STMIK Palangkaraya. Jurnal Teknologi Technoscientia ISSN: 1979-8415 Vol. 8 No. 2 Februari 2016

[4] Hidayat, W., Wicaksono, R., \& Julian, R. Media Pembelajaran Perakitan Pc Dengan Animasi 3d Menggunakan 3dsmax Untuk Meningkatkan Prestasi Belajar Siswa Di Smk. SENSI Journal, 2(1), 92-97. Retrieved from http://ejournal.raharja.ac.id/index.php/sens i/article/view/743, 2016.

[5] Lalu Herman Susandi dan Zinnurain (2019) Pengaruh Media 3ds Max Maker Terhadap Hasilbelajar Siswa, Program Studi Teknologi Pendidikan FIP IKIP Mataram, Jurnal Teknologi Pendidikan Volume 4 Nomor 1 Edisi April 2019 PISSN : 2503-0620 E-ISSN : 2656-1417

[6] Rizky I. Descarian, Dedi Rohendi dan Yusep Sukrawan, Pengembangan Multimedia Animasi Diffusion Coatinguntuk Pembelajaran Teknik Pelapisan, Universitas Pendidikan Indonesia, Journal of Mechanical Engineering Education, Vol. 6, No. 1, Juni 2019 